process is sometimes a chronic one but rapidly spreading necrotising infection may occur with destruction of skin, fat, and muscle. The response to metronidazole is striking and early diagnosis with prompt treatment will prevent further destruction. The diagnosis should be considered if spreading ulceration occurs in the perineum or abdominal wall. Stool examination, serology, scrapings from the ulcer, and biopsy are of value in confirming the diagnosis of amoebiasis but, if this seems the likely cause, treatment in cases with rapidly spreading ulceration should begin immediately without waiting for the results of these tests.

Cutaneous amoebiasis may occasionally occur in a patient without previous intestinal infection by external inoculation of a wound..$^{35}$ Penile and vaginal amoebiasis occurring in adults is thought to be venereal in origin. ${ }^{135}$

The vulva is particularly vulnerable to infection in the small child still wearing a nappy as this holds infected stools in close contact with the perineum. ${ }^{2-3} 5-6$ Pronounced destruction can occur. In the case reported here the vulval ulceration and perianal ulceration were separated by a bridge of skin and there was extensive induration in the ischiorectal fossa and pelvis with destruction of the anal muscles, pelvic floor, and rectovaginal septum.

\section{A normal paediatric amylase range}

\section{P J AGGETT AND FRANCES TAYLOR}

The Hospital for Sick Children, London

SUMMARY A normal paediatric range of plasma $\alpha$-amylase activity was determined using the Phadebas blue starch method. The range for children over one year was 98-405 IU/1. Plasma amylase activity increased throughout infancy. Mature levels of activity were observed in some children by age 2 months and in most of them by 9 months.

The Phadebas amylase test (Pharmacia) is a simple and accurate method for determining plasma or serum $\alpha$-amylase activity. ${ }^{1-2}$ Although the original report on this method gave a normal range for individuals under 20 years, a satisfactory normal range for children has not been established. This report describes such a range.

Plasma was obtained from heparinised blood samples taken from 116 children; 54 from children
The history that the initial presentation had been as a perianal abscess suggests that the invasive process started more deeply within the anus or rectum.

\section{References}

1 Wilkinson D S. Diseases of the perianal and genital regions. In: Rook A, Wilkinson D S, Ebling F J G, eds. Textbook of dermatology. 2nd ed. Oxford: Blackwell Scientific Publications, 1972: 1747-90.

2 Harmon $R$ R M. Parasitic worms and protozoa. In: Rook A, Wilkinson D S, Ebling F J G, eds. Textbook of dermatology. 2nd ed. Oxford: Blackwell Scientific Publications, 1972: 829-30.

3 Biagi F F, Martuscelli A R. Cutaneous amebiasis in Mexico. Int J Dermatol 1963; 2: 129-36.

4 Ruiz-Moreno F. Perianal skin amebiasis. Dis Col Rect 1967; 10: 65-9.

5 Biagi F. Cutaneous amoebiasis. In: Essays on tropical dermatology. Vol. 1. Amsterdam: Exerpta Medica, 1969: $205-9$.

- Chacon R A. Cutaneous amoebiasis. Mod Probl Paediatr 1975; 17: 259-61.

7 Sunarwan I. A case of cutaneous amoebiasis. Dermatologica $1975 ; 151$ : $253-6$.

8 Adams E B, MacLeod I N. Invasive amebiasis. I. Amebic dysentery and its complications. Medicine (Baltimore) 1977; 56: 315-23.

Correspondence to Dr J M Wynne, University of Queensland, Department of Surgery, Clinical Sciences Building, Royal Brisbane Hospital, Herston, Queensland, Australia 4029. immediately after induction of general anaethesia, 47 from children having a venepuncture for other investigations, and 15 from cord blood of term normal neonates. Children with renal, hepatic, or gastrointestinal disease or those with a history of fits or recent infection were excluded. 53 children were under one year, the eldest was 15 years.

Plasma total $\alpha$-amylase activity was measured by the Phadebas blue starch method according to the manufacturer's instructions. The calibration was adjusted to enable the determination of activities below $30 \mathrm{IU} / \mathrm{l}$.

Statistical comparisons were made using the Wilcoxon rank sum test.

\section{Results}

Plasma $\alpha$-amylase activity was lowest in the neonates 


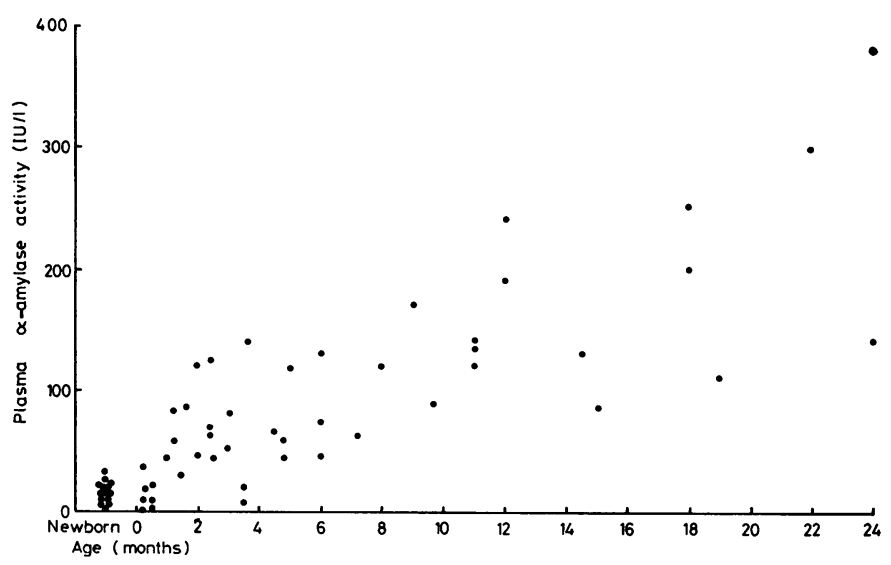

Fig. 1 Plasma $\alpha$-amylase activity (IU/l) in children aged 2 years and under related to age.

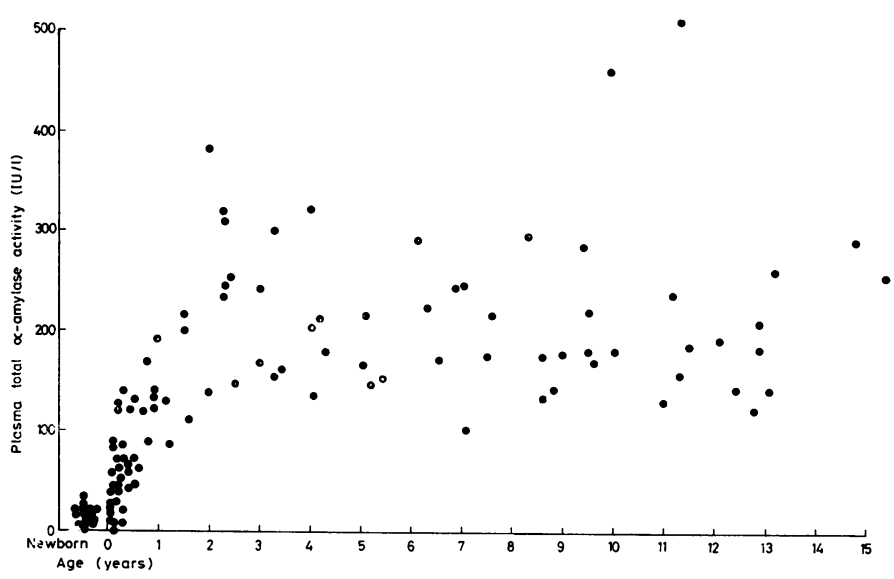

Fig. 2 Plasma $\alpha$-amylase activity $(I U / l)$ in all children related to age.

and increased during infancy (Fig. 1). After age 9 months only two values were below the range determined for children over age one year. Activities in this established range were present earlier in many cases and were observed in 2 children as early as age 2 months.

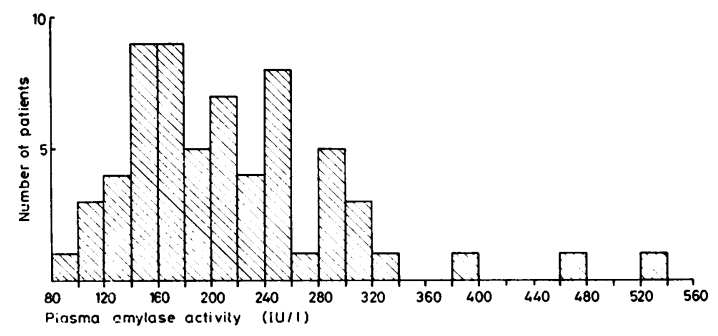

Fig. 3 Distribution of plasma $\alpha$-amylase activity (IU/l) in children over one year of age.
The $\alpha$-amylase activity in all children is shown in Fig. 2, the distribution of activities in children over age one year was positively skew (Fig. 3), but satisfactorily normalised with logarithmic transformation to give a normal plasma $\alpha$-amylase activity of 98-405 IU/l. There was no difference between the activities detected in the surgical and nonsurgical patients, or between boys and girls.

\section{Discussion}

The range established is broader and higher than the adult range of 70-300 IU/l, which is given by the manufacturers and is based on that determined by Ceska et al. ${ }^{1}$

Somogyi $^{3}$ first noted low serum amylase activity in neonates and infants, which increased to adult levels by one year. This report illustrates that it is not unusual to discover adult levels of plasma amylase activity in children much younger than one year and 
that these levels are achieved in most children by 9 months.

Serum amylases can be separated into 4 to 6 isoenzymes by chromatographic, isoelectric focusing, and electrophoretic techniques. ${ }^{4}$ The two main groups of these isoenzymes are the pancreatic and nonpancreatic components which are present in the ratio $1: 2$. Most of the nonpancreatic isoenzymes are of salivary origin. ${ }^{5}$ While the activity of both these components increases steadily with age, Skude ${ }^{6}$ reported that mature levels of activity may not be achieved until 5 years for the salivary component or 10 years for the pancreatic isoenzymes. If this is the case, it is intriguing to find the mature range of total amylase activity present at one year.

Isoenzyme analysis is too time-consuming and complicated for routine use and the total amylase activity, although relatively insensitive for differential diagnosis, remains the principal investigation for acute pancreatitis.

Patients with Shwachman's syndrome of congenital pancreatic exocrine insufficiency have reduced plasma amylase activities compared with normal children. ${ }^{7}$ Low levels of amylase activity may therefore be of value in deciding whether to perform formal pancreatic function tests in children with malabsorption in whom cystic fibrosis has been excluded.
We thank Dr W J Glover, Dr E F Battersby, and other members of the anaesthetic department for taking blood specimens, and Professor Barbara E Clayton and Dr J V Leonard for advice.

P J A was supported by the Medical Research Council.

\section{References}

1 Ceska M, Brown B, Birath K. Ranges of $\alpha$-amylase activities in human serum and urine and correlations with other $\alpha$-amylase methods. Clin Chim Acta 1969; 26: 445-53.

2 Irie A, Hunaki M, Bando K, Kawai K. Determination of amlyase activity in serum and urine using blue starch substrate. Clin Chim Acta 1972; 42: 63-6.

3 Somogyi M. Diastatic activity of human blood. Arch Intern Med 1941; 67: 665-79.

4 Warshaw A L. Serum amylase isoenzyme profile as a differential index in disease. J Lab Clin Med 1977; 90: 1-3.

5 Levitt M D, Ellis C, Engel R R. Isoelectric focusing studies of human serum and tissue isoamylases. $J$ Lab Clin Med 1977; 90: 141-52.

- Skude G. Sources of the serum isoamylases and their normal range of variation with age. Scand J Gastroenterol 1975; 10: 577-84.

7 Aggett P J, Cavanagh N P C, Matthew D J, Pincott J R, Sutcliffe J, Harries J T. Shwachman's syndrome: a review of 21 cases. Arch Dis Child 1980; 55 : (in press).

Correspondence to Dr P J Aggett, Physiology Department, Marischal College, Aberdeen AB9 1AS. 